\title{
Determinants of out-of-pocket health expenditure and their welfare implications in a South African context
}

\begin{tabular}{|c|c|}
\hline \multicolumn{2}{|c|}{$\begin{array}{l}\text { Authors: } \\
\text { Ali Babikir }{ }^{1} \\
\text { Ali Satty } \\
\text { Henry Mwambi }\end{array}$} \\
\hline \multicolumn{2}{|c|}{$\begin{array}{l}\text { Affiliations: } \\
{ }^{1} \text { Department of Mathematics } \\
\text { and Statistics, College of } \\
\text { Science, Taibah University, } \\
\text { Saudi Arabia }\end{array}$} \\
\hline \multicolumn{2}{|c|}{$\begin{array}{l}{ }^{2} \text { School of Mathematics, } \\
\text { Statistics and Computer } \\
\text { Science, University of } \\
\text { KwaZulu-Natal, South Africa }\end{array}$} \\
\hline \multicolumn{2}{|c|}{$\begin{array}{l}\text { Corresponding author: } \\
\text { Ali Babikir, } \\
\text { ababikir@taibahu.edu.sa }\end{array}$} \\
\hline \multicolumn{2}{|c|}{$\begin{array}{l}\text { Dates: } \\
\text { Received: } 12 \text { Apr. } 2017 \\
\text { Accepted: } 25 \text { Sept. } 2017 \\
\text { Published: } 17 \text { May } 2018\end{array}$} \\
\hline \multicolumn{2}{|c|}{$\begin{array}{l}\text { How to cite this article: } \\
\text { Babikir, A., Satty, A. \& } \\
\text { Mwambi, H., 2018, } \\
\text { 'Determinants of out-of- } \\
\text { pocket health expenditure } \\
\text { and their welfare implications } \\
\text { in a South African context', } \\
\text { Journal of Economic and } \\
\text { Financial Sciences 11(1), } \\
\text { a177. http://dx.doi. } \\
\text { org/10.4102/jef.v11i1.177 }\end{array}$} \\
\hline \multicolumn{2}{|c|}{$\begin{array}{l}\text { Copyright: } \\
\text { (C) 2018. The Authors } \\
\text { Licensee: AOSIS. This } \\
\text { is licensed under the } \\
\text { Creative Commons } \\
\text { Attribution License. }\end{array}$} \\
\hline \multicolumn{2}{|l|}{ Read online: } \\
\hline 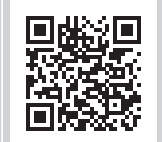 & $\begin{array}{l}\text { Scan this QR } \\
\text { code with your } \\
\text { smart phone or } \\
\text { mobile device } \\
\text { to read online. }\end{array}$ \\
\hline
\end{tabular}

This study aims to quantify the extent of catastrophic household health expenditures on welfare and determine factors influencing it. A logistic regression model based on the logit link function was used to predict the probability of catastrophic health expenditure occurrence. A comparison between 2008 and 2012 health status of adults shows that there was a sizable improvement of the health status of individuals. The high level of catastrophic health expenditure may be associated with the low share of prepayment in national health expenditure, adequate availability of services and a high level of poverty which for South Africa is $46.2 \%$ according to the Statistics South Africa report (2015). Major factors determining the catastrophic expenditure besides poverty were spending on hospitalisation and medical supplies. Thus, reducing catastrophic expenditures requires an increase in financial protection offered to the poor through expanding government-financed benefits for the poor such as implementation of the Social Health Insurance (SHI) scheme, which will cover all poor households.

\section{Introduction}

South Africa is one of the upper-middle-income countries, according to the World Bank classification, with Gross National Income (GNI) per capita of \$6800 in 2014. South Africa has placed strong emphasis on health care ever since the first democratic elections in 1994. The development of the National Health System (NHS) has been central to proposals for the restructuring of its health sector. South Africa's health system has witnessed a number of policy interventions with the aim of advancing the NHS' policy agenda. Considerable progress has been made towards the strengthening of such a system with respect to service delivery, organisation and funding of health services (Botha 2008). Firstly, access to healthcare has become a major concern for the government that it should be of the constitutional right that every person in South Africa should access optimal health care. Secondly, primary health care services have increased dramatically over the years, with an increase of more than 20 million patients visiting public health facilities annually compared with 2002 according to National Department of Health 2007 report. There has also simultaneously been a large increase in the number of healthcare personnel serving rural communities by 31710 in terms of doctors, nurses, pharmacists and ambulance personnel. Since 2004 and 2005, there are over 40 hospitals being rehabilitated through the hospital revitalisation programme. Many of the elements of the District Health Services (DHS) have been implemented, such as the alignment of health district boundaries, organisation of DHS and an establishment of referral systems. Finally, in terms of the 2003 Organisational Plan for Comprehensive HIV and AIDS Care, Management and Treatment and its successor, the National Strategic Plan 2007-2011, there has been significant progress made towards providing access to treatment and care (Botha 2008). Although there is considerable progress in several components, key failures of the public health system are still being felt. Even with the implementation of numerous well-documented policies, people are still faced with challenges of inadequate and inequitable access to health care services, with respect to public health systems, attributed to inefficiencies, poor-quality care, under-financing and the remaining lack of social solidarity within the system (Botha 2008).

Even with a sound health care system in place, whereby it is the constitutional right for every person to have access to health care, the question still remains as to how people will be able to finance such health care. Under the apartheid era, the exclusion of Africans at all levels to adequate health care or facilities compounded by the low-wage income that they were paid ensured that even with adequate services many would not be able to afford them. This has however changed ever since 1994, whereby everyone is expected to have access to free and affordable public health facilities; yet, however, the data seem to tell a different story. According to Pandayachee (2006), the reason as to why $24.0 \%$ of the elderly do not seek health care services is cited as inadequate funds, while $31.0 \%$ said that either the clinic or the hospital was too far and that they were not able 
to afford the transport cost among Africans. As for the adults, the results were even more shocking that the reason why $54.0 \%$ people do not seek health treatment was the lack of funds and $29.0 \%$ said that the clinic or the hospital was too far away. Unemployment level is still a major concern, such that many people are unable to provide themselves the necessities of life, let alone to have the funds for health care treatment. Nyonator and Kutzin (1999) have labelled the system in which the poor continually fail to have access to health facilities because of lack of funds and the other side of the income group have easy access, as 'sustainable inequality', which has also been discussed by Pandayachee (2006).

Over the past couple of decades, many studies have been performed with regard to the issue of out-of-pocket (OOP) health expenditure (as in $\mathrm{Xu}$ et al. 2003b). The main issue at hand is: 'when does OOP health expenditure become catastrophic?' OOP health expenditure is not much of a concern until it has severe impact on the household expenditure patterns and budget, and in more severe cases households may need to sell assets in order to finance the accumulated health cost; thus, OOP health expenditure may have a negative impact on welfare and may force households into poverty. In this case, it may cause households to make a difficult choice between their standard of living or health, and in either case it will have a negative impact on the overall welfare of the household as both will impact the household's life style. One of the greatest concerns among low-income households is their loss of welfare because of such payments, as generally low-income households do not have the financial requirements for comprehensive third party insurance: therefore, the question arises as to whether public health facilities and government are able to provide enough support (Xu et al. 2003a).

According to various estimates of the World Health Organization (WHO), the general South African government expenditure on health as percentage of total expenditure on health for 2000 and 2013 stood at 41.3 and 48.4, respectively, where the private expenditure on health as percentage of total expenditure on health for 2000 and 2013 was 58.7 and 51.6 , respectively. The OOP health expenditure as percentage of total expenditure on health for 2000 and 2013 reached 22.2 and 13.8, respectively. But since, growing public spending for health increases along with economic growth observed in the country during recent years, this led to a noticeable decrease in the share of private expenditure in total health expenditure. The poverty headcount ratio at national poverty lines represents $53.8 \%$ of the population according to World Bank (2010) statistics. Based on these statistics, the decreasing OOP spending in the health sector became the significant factor contributing to impoverishment of South African households based on that high poverty ratio. This article attempts to evaluate the prevalence of catastrophic health expenditure and its determining factors.

The rest of the article is organised as follows: in the 'Methods' section we review the method, the structure of survey used and the health expenditure and how to determine the catastrophic health expenditure. The 'Statistical analysis' section provides statistical analysis and results. A discussion is reported in the 'Discussion' section. The 'Conclusion' section provides a conclusion of the main findings of the article.

\section{Methods}

We used the National Income Dynamics Study (NIDS), which is the first national household panel study in South Africa. The NIDS is implemented by the Southern Africa Labour and Development Research Unit (SALDRU) based at the University of Cape Town's School of Economics. The study began in 2008 and is carried out every two years; the last survey data being released in September 2013. A total of 8040 households, with a total of 32633 individuals, were interviewed. The focused survey was aimed at estimating household and individual income, expenditure, assets, access to services, education, health and other dimensions of well-being.

\section{Structure of the National Income Dynamics Study questionnaire}

The NIDS used a combination of household and individuallevel questionnaires. Four types of questionnaires were used: household questionnaire was about household affairs and particularly household spending. Adult questionnaire was applied to all present continuing sample members and other household members resident in their households who were aged 15 years or over. Proxy questionnaire: should an individual qualifying for an adult questionnaire not present, then a proxy questionnaire was taken on their behalf with a present resident adult. Child questionnaire collected information about all continuing sample members and residents in their household younger than 15 years. In this article, we only used the household and adult questionnaires and consider particular sections of the questionnaires such as (1) self-reported health status of household members, (2) availability of health care facilities to the household, (3) last medical check-up by any household member, which provided information for each household member who had a medical consultation. This section primarily helped us to evaluate service utilisation (not expenditures) and (4) services used and associated costs for illnesses that occurred during 30 days prior to the interview. This information was collected for each person who had been sick and used health services or spent any money on health care in the last 30 days. This section primarily helped us to estimate health care expenditures for health insurance, medical professionals, hospital fees and medical supplies.

\section{Type of expenditures used in the National Income Dynamics Study}

The survey instrument allowed for looking at the following average monthly expenditures (on a household level): inpatient, outpatient and recurrent costs for chronic conditions. Each group of expenditure was also partitioned into expenditures for medications, medical supplies and diagnostic and consultation fees. 


\section{Catastrophic health expenditure}

The concept of catastrophic health expenditure has been defined as occurring once OOP payments cross the estimated threshold share of household expenditure at which the household is forced to sacrifice other basic needs, sell assets, incur debt or be impoverished (Berki 1986; Wagstaff \& Doorslaer 2003; Wyszewianski 1986). Thresholds used by different researchers to estimate catastrophic health payments vary from $5.0 \%$ to $20.0 \%$ of total income, or $12.5 \%-50.0 \%$ of non-subsistence income for poor families spending $60.0 \%$ of their income on food ( $\mathrm{Xu}$ et al. 2007). Although there is no final consensus on the choice of the threshold, for this article we employ a more frequently used threshold proposed by the researchers at WHO in their 'fair financing' framework (Xu et al. 2003b). Xu et al. (2003b) define catastrophic health expenditure in relation to the households' non-food expenditures. The health expenditure is determined as catastrophic if a household's financial contributions to healthcare equal and/or exceed $40.0 \%$ of non-food expenditure or capacity to pay (CTP). A CTP is estimated after subtracting subsistence expenditure from monthly household expenditure (i.e. consumption) obtained from NIDS.

Subsistence expenditure for the purposes of our calculations corresponds to the average food expenditure of the households in the 45th and 55th percentiles, adjusted to the size of the given household (Xu et al. 2003b). To adjust for household size, we used the Consumption Equivalence Scale and the methodology suggested by Xu et al. (2003b). To compare households with different economic status, expenditure quintile groups were defined through ranking household monthly expenditure per adult equivalent (dividing household monthly expenditure by adult equivalent household size).

\section{Statistical analysis}

Statistical Package for Social Science (SPSS) software was used for statistical analysis. A descriptive analysis was undertaken to understand occurrence of illness, care-seeking behaviour and size of OOP payments on a household level. A logistic regression (logit) model was used to predict probability of catastrophic health expenditure occurrence. Based on evidence available in the literature, we assumed that households having catastrophic expenditure are affected by patterns of illness such as facing expenditure because of chronic illness, facing cost of hospitalisations, household characteristics which include household size, their vulnerability status (eligibility to government grant), education of the head of the household and households' economic status (measured by quintile group), among others (Su, Kouyaté \& Flessa 2006; Wter, Anderson \& Mays 2004). All these variables were entered in the logit model using forward stepwise entry function in the SPSS software. A variable was included in the model if the probability of its score statistic for significance was less than 0.05 and was removed if the probability was greater than 0.1 . The stepwise entry-removal of the various explanatory variables allowed for identification of those that had statistically significant influence on the probability of determining catastrophic health expenditure. These variables were the following: (1) households with expenditure for treating chronic illness which include tuberculosis (TB), diabetes, blood pressure, stroke, heart problems and cancer; (2) households that faced hospital expenditure; (3) households that faced medical supplies expenditure; (4) households that spent money on traditional healers - where it is common especially in rural area; (5) households that received government grants (all included in the model as dichotomous variables); and (6) quintile groups of the household income.

\section{Results}

A total of 22481 individuals resided in the 10236 households surveyed and the mean household size was 3.66 (SD 1.4). The individual adult questionnaire provided information about the income classification of the households (see Table 1). The survey asked respondents to distinguish between chronic and acute illnesses, with the former being defined as one that had lasted or was expected to last more than 1 year. Correspondingly, the results for the two were reported separately. The proportion of people who reported suffering from a chronic illness was high, namely $39.0 \%$ from the average income respondents, followed by $32.4 \%$ from those below average income respondents and $19.8 \%$ of the poorerfar below average income - respondents with chronic diseases; overall $26.0 \%$ of the population have chronic disease, with $11.0 \%$ of the population reporting suffering from two or more chronic illnesses. There was a wide range of chronic conditions reported, but the most common chronic diseases were hypertension, TB and diabetes, which accounted for about $70.0 \%$ of all occurrences. Some $11.85 \%$ of the respondents reported having had an acute sickness during the last 30 days. Richer households were slightly more likely to report illness than poor households, although this probably reflects different perceptions of illness. This is consistent with other studies elsewhere showing that the proportion of self-reported illness is less significant among the poor than among the richer. Even though the poor might suffer more illness than the richer, the non-poor perceive

TABLE 1: Key indicators by income classification of households (individual level - adult).

\begin{tabular}{|c|c|c|c|c|c|c|}
\hline Indicator & $\begin{array}{l}\text { Much below average } \\
\text { income (poorer) }\end{array}$ & $\begin{array}{l}\text { Below average } \\
\text { income }\end{array}$ & $\begin{array}{l}\text { Average } \\
\text { income }\end{array}$ & $\begin{array}{l}\text { Above average } \\
\text { income }\end{array}$ & $\begin{array}{l}\text { Much above average } \\
\text { income (richest) }\end{array}$ & $\begin{array}{l}\% \text { of total } \\
\text { population }\end{array}$ \\
\hline$\%$ that the last consultation paid by medical aid & 3.7 & 14.5 & 29.9 & 36.0 & 22.0 & 24.1 \\
\hline$\%$ that the last consultation paid by respondent & 69.0 & 65.1 & 51.4 & 48.3 & 45.0 & 55.7 \\
\hline$\%$ that the last consultation paid by household member & 8.0 & 6.4 & 7.6 & 4.5 & 15.0 & 7.4 \\
\hline$\%$ received some sort of government grants & 22.2 & 34.1 & 33.4 & 5.7 & 2.4 & 20.7 \\
\hline$\%$ with chronic diseases & 19.8 & 32.4 & 39.0 & 6.6 & 2.1 & 26.0 \\
\hline
\end{tabular}


themselves to suffer as much and to have even more illness than the poor (Sen 2002).

The high percentage of people who received medical aid payments for their last consultation were those with above average income $(36.0 \%)$, followed by average and richest - above average income - with $29.9 \%$ and $22.0 \%$, respectively; the poorer represent $3.7 \%$, which was the lowest percentage of people who paid their last consultation fee by the medical aid; this lowest percentage of poor is the real reflection of the lower number of medical aid members of this group. In contrast, the poorer represent the highest percentage (69.0\%) of income groups that paid consultation fees by the respondents, the high burden on the poor increased the impoverishment of the lower income groups. On the contrary, the richer represent the lowest percentage $(45.0 \%)$ of people who made their own payment. Regarding the financial support, the government provides some sort of grants to enhance the poor standard of living, with the surprising results that the poorest received fewer grants than the average income group. This contradicted result may have attributed to the fact that the poorest residents in rural and traditional areas had limited access to government services. Overall, we found that in total around $21.0 \%$ of the population received government grants (see Table 1).

\section{Healthcare spending}

The survey captured monthly health care expenditure that was divided into by several categories: (1) cost of medical aid, (2) cost of outpatient care when healthcare provider was consulted, (3) cost of hospital fee and (4) costs of drugs and some medical items. Mean costs in all four categories were lowest among the poorest quintile groups and highest among the richest (see Table 2).

The survey findings also indicate possible problems in targeting, despite the fact that the survey was not designed specifically for benefit incidence analysis. Table 1 shows that while more than $28 \%$ of households from lowest income groups are beneficiaries of the government grants, while at the same time $2.4 \%$ to $5.7 \%$ of rich and above average income households, representing the highest income groups, are also recipients of the grants. This finding should be interpreted with caution, which implies more comprehensive assessment of a household economic status for eligibility of government grants. Further inquiry in this issue is warranted, but this is beyond the focus of this article.

\section{Health insurance coverage}

In this section, we aim to assess the proportion and the characteristics of the population covered by any kind of medical insurance. We will focus on household and individual coverage. The coverage within households is evaluated through the survey question that captures information about the money spent in the last month for medical insurance. Out of 8040 respondents, 635 respondents had no payment for medical insurance in the last 30 days. It turns out that $92.0 \%$ of households do not belong to any health insurance. In fact in South Africa, the payment of all insurance types is made on a monthly installment basis. If we turn to individual coverage, only $9.2 \%$ of adults benefit from medical insurance coverage. According to income classifications, however, large variations of those individuals covered are to be found. About $62.9 \%$ of covered individuals are from the average income group. The poor and the poorest groups - that is the below and far below average income groups - represent $13.8 \%$ and $1.9 \%$ of the insured population, respectively (see Figure 1).

\section{Health status}

Health status of adults is assessed through a subjective measure that is captured by the survey through a question dedicated to reporting the health status of respondents. In addition, we compared the health status of adults in 2012 with their status in 2008. The comparison presented in Table 3 reveals an improvement in health status of people between 2008 and 2012; we noticed that there was an increase in excellent, very good and good health status in 2012 compared with 2008 data. In contrast, there was a decrease in the percentage of adults with poor and fair health status in 2012 compared with 2008 data (see Table 3). Poor health status decreased during this period, in both levels, the individual income classification as a

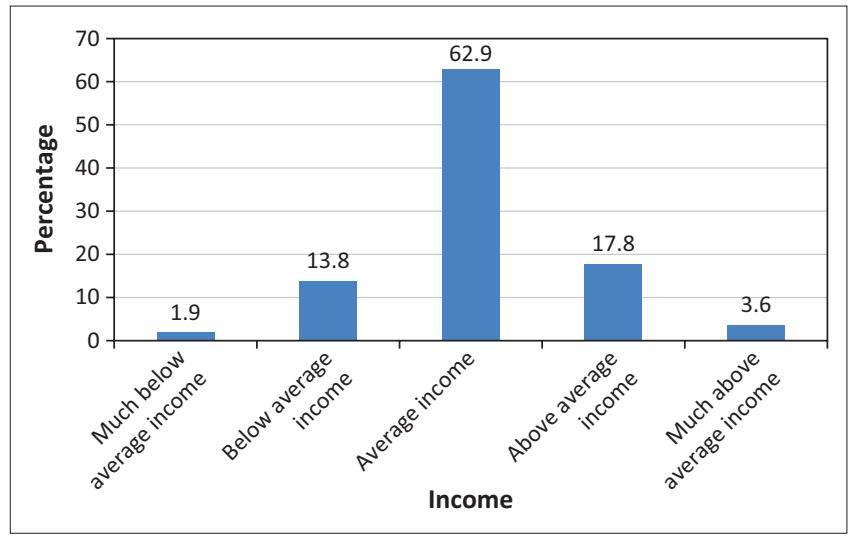

FIGURE 1: Percentage of individuals covered by health insurance by income classifications.

TABLE 2: Household expenditure characteristics mean in the last 30 days.

\begin{tabular}{|c|c|c|c|c|}
\hline Quintile group & $\begin{array}{l}\text { Mean of amount spent on health } \\
\text { insurance (ZAR) }\end{array}$ & $\begin{array}{c}\text { Mean of amount spent on medical } \\
\text { professionals (ZAR) }\end{array}$ & $\begin{array}{l}\text { Mean of amount spent on hospital } \\
\text { fees (ZAR) }\end{array}$ & $\begin{array}{c}\text { Mean of amount spent on medical } \\
\text { supplies (ZAR) }\end{array}$ \\
\hline Poorest & 479.50 & 241.82 & 88.75 & 53.42 \\
\hline 2 & 619.00 & 162.89 & 86.67 & 80.50 \\
\hline 4 & 573.33 & 368.33 & 30.00 & 151.67 \\
\hline Richest & 1839.89 & 496.64 & 3188.56 & 454.92 \\
\hline
\end{tabular}

ZAR, South African Rand. 
TABLE 3: Comparison between 2008 and 2012 surveys - Health status and income classification (individual level - adult).

\begin{tabular}{|c|c|c|c|c|c|c|}
\hline $\begin{array}{l}\text { Respondent's health } \\
\text { status }\end{array}$ & $\begin{array}{l}\text { Much above average } \\
\text { income }\end{array}$ & $\begin{array}{c}\text { Above average } \\
\text { income }\end{array}$ & Average income & $\begin{array}{c}\text { Below average } \\
\text { income }\end{array}$ & $\begin{array}{l}\text { Much below average } \\
\text { income }\end{array}$ & Total \% \\
\hline \multicolumn{7}{|l|}{ Excellent } \\
\hline 2008 & 0.98 & 1.93 & 11.36 & 7.82 & 4.52 & 29.08 \\
\hline 2012 & 0.86 & 2.41 & 11.96 & 8.79 & 5.62 & $30.09 \dagger$ \\
\hline \multicolumn{7}{|l|}{ Very good } \\
\hline 2008 & 0.33 & 2.03 & 9.87 & 7.83 & 3.68 & 25.13 \\
\hline 2012 & 0.44 & 2.05 & 11.42 & 8.98 & 5.92 & $29.10 \dagger$ \\
\hline \multicolumn{7}{|l|}{ Good } \\
\hline 2008 & 0.43 & 1.32 & 9.45 & 7.54 & 3.74 & 24.05 \\
\hline 2012 & 0.60 & 1.84 & 11.50 & 8.37 & 5.80 & $28.58 \dagger$ \\
\hline \multicolumn{7}{|l|}{ Fair } \\
\hline 2008 & 0.17 & 0.52 & 4.09 & 4.93 & 2.67 & 13.16 \\
\hline 2012 & 0.24 & 0.58 & 2.94 & 2.99 & 1.92 & $8.83 \dagger$ \\
\hline \multicolumn{7}{|l|}{ Poor } \\
\hline 2012 & 0.05 & 0.15 & 0.92 & 1.16 & 0.96 & $3.33 \dagger$ \\
\hline \multicolumn{7}{|l|}{ Total } \\
\hline 2008 & 2.05 & 6.02 & 36.62 & 31.03 & 17.41 & 99.4 \\
\hline 2012 & 2.2 & 7.0 & 38.8 & 30.3 & 20.2 & $98.5 \dagger$ \\
\hline
\end{tabular}

$\dagger$, indicate the improvement of 2012 data compared with 2008 data.

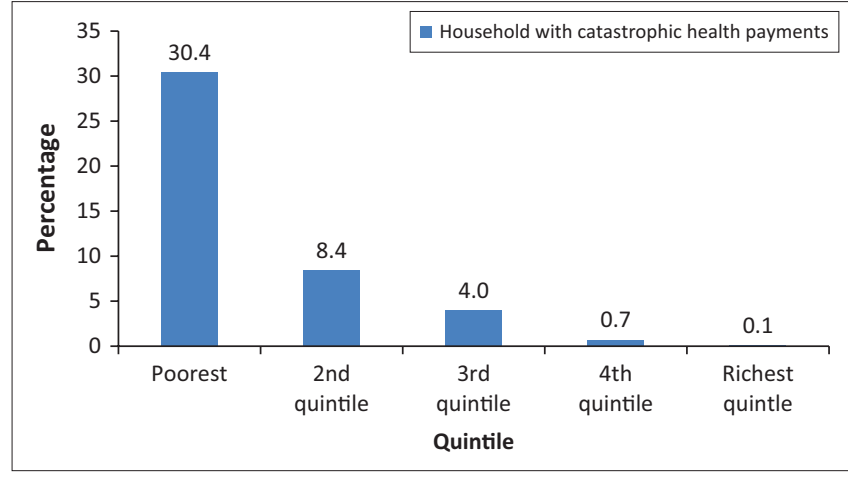

FIGURE 2: Proportion of households facing catastrophic expenditures by expenditure quintiles.

percentage of total population, the percentage reduction in the poor health status stood around 58.0\% between 2008 and 2012. The reduction in the percentage of adults with fair health status was around $33.0 \%$ during the period. The percentage of those with excellent, very good and good health status in 2012 increased by $3.5 \%, 15.8 \%$ and $18.8 \%$, respectively, compared with 2008 data. The change in the health status could be an indication that government's efforts to deliver better health coverage to the poor have rendered some positive results.

\section{Catastrophic expenditures on health}

In our sample, $13.4 \%$ of the households faced catastrophic health care expenditure. The poorest quintile had the highest share of $30.4 \%$, while the second, third and fourth quintiles' allocation was $8.4 \%, 4.0 \%$ and $0.7 \%$, respectively. On the contrary, only $0.1 \%$ of the richest households faced catastrophic health care expenditure (see Figure 2).

\section{Determinants of catastrophic health expenditures}

Logistic regression revealed (see Table 4) that the odds of facing catastrophic expenditure were 13.9 and 7.8 times higher among the poorest households and households that incurred expenditure for medical supplies. In other words, the main determinants of catastrophic expenditure were being one of the poorest households and the household that spent money on medical supplies. The odds of facing catastrophic expenditure were 3.2 times higher among households having incurred expenditure on hospitalisation. Households in the richest quintile were far less likely to face catastrophic expenditure when compared with the poorest quintile and as the households' monthly consumption increased, the probability of facing catastrophic health expenditure declined. Finally, the odds of facing catastrophic health spending for medical supplies were almost two, eight and eight times higher compared with those households that incurred expenditure for hospitalisation, expenditure for health insurance and expenditure on traditional healers, respectively. Looking at the coefficients of the logit model, we find that spending money on health insurance protects against catastrophic expenditure; also spending money on traditional healers saves from facing catastrophic expenditure: this is because of the far low cost of traditional healer compared with medical professionals and the majority of rural residents believe on them. The unpredictable result is that the grants the households received from the government are not contributing to alleviate the catastrophic health expenditures that are attributed to the nature of the grants, which is not dedicated to health support and expenditure.

\section{Discussion}

We first consider the implications of the results for South Africa, but first, possible limitations of the study are considered. Firstly, the major limitation is that the survey is a household income and expenditure survey which did not specifically look at health care expenditure and utilisation. Thus, a bias in non-health care surveys may underestimate spending levels on health. Secondly, the survey tool did not account for (1) the portion of the cost of services when paid 
Table 4: Estimated coefficients in logit model for (catastrophic health care expenditure $=1$ ) household-level data.

\begin{tabular}{|c|c|c|c|c|c|c|}
\hline Variables & B & Wald & Sig. & Odd ratio & \multicolumn{2}{|c|}{$95 \% \mathrm{Cl}$ for odd ratio } \\
\hline Intercept & -1.039 & 38.414 & 0.000 & 0.354 & - & - \\
\hline Poorest quintile & 2.632 & 700.527 & 0.000 & 13.895 & 11.435 & 16.884 \\
\hline 2nd quintile & -0.186 & 6.001 & 0.017 & 0.830 & 0.641 & 1.074 \\
\hline 3rd quintile & -0.972 & 45.199 & 0.000 & 0.378 & 0.285 & 0.502 \\
\hline 4th quintile & -1.222 & 14.006 & 0.000 & 0.295 & 0.155 & 0.559 \\
\hline Richest quintile & -3.782 & 28.334 & 0.000 & 0.023 & 0.006 & 0.092 \\
\hline Money paid on hospitalisation & 1.170 & 5.906 & 0.027 & 3.222 & 2.713 & 3.854 \\
\hline Money spent on medical supplies & 2.056 & 8.750 & 0.013 & 7.815 & 7.009 & 8.708 \\
\hline Money spent on traditional healers & -0.182 & 16.584 & 0.000 & 0.834 & 0.739 & 0.831 \\
\hline $\mathrm{HH}$ received government grant & 0.251 & 17.968 & 0.000 & 1.285 & 1.144 & 1.443 \\
\hline Log likelihood & 2.182 & - & - & - & - & - \\
\hline Pseudo $R^{2}$ & 0.226 & - & - & - & - & - \\
\hline Hosmer-Lemeshow test & $\begin{array}{c}13.44 \\
P=0.09\end{array}$ & - & - & - & - & - \\
\hline Observations & 8.040 & - & - & - & - & - \\
\hline
\end{tabular}

$\mathrm{HH}$, household; Sig., significant at $1 \%$.

by third party payers (insurance companies, government programmes, etc.); (2) the household expenditures on chronic diseases such as TB, HIV and diabetes were not captured by the survey; (3) the government subsidies and spending on the household level and its impact on the prevalence of catastrophic health spending cannot be determined; and (4) the survey did not capture information about the HIV and/or ADIS. Despite South Africa only having $0.7 \%$ of the world's population, it carries $17.0 \%$ of HIV infected people in the world. The HIV prevalence is 23 times the global average, while the TB infection rate is among the highest in the world. Moreover, the TB and HIV and/or AIDS co-infection rate is one of the highest in the world, which stands at 73.0\%. As a result, life expectancy in South Africa has declined over a number of years. HIV and/or AIDS has also contributed significantly to high maternal and child mortality rates. Thirdly, the household resident location is important as the people in urban areas are more likely to face catastrophic health expenditure as the cost and level of health services are higher compared with those in rural areas. Finally, all diseases are self-reported and while they may sometimes be based on diagnoses given by doctors to the respondents, in other cases they may not be.

Catastrophic health expenditure could only be measured when health services are used and costs of service provision are paid. Many poor households simply avoid seeking care because of financial considerations; therefore, the presented results could underestimate the reality. Saksena, $\mathrm{Xu}$ and Carrin (2006) also acknowledged this limitation and proposed broader framework for catastrophic health expenditure. They estimated the total potential (unobserved and observed) incidence of catastrophic health expenditure in Kenya by combining the reported OOP health expenditures for those who utilised health services and the predicted OOP expenditures for those who did not use health services but reported illness. They found a significant difference between the total number of households potentially facing catastrophic expenditure and the households that actually faced catastrophic expenditure. This difference was more profound for households from poorest quintile - three times as many households would have faced the catastrophic expenditures in case of use of health services $19.0 \%$ versus $6.6 \%$. However, the risk of the catastrophic health expenditures for households in the richest quintile who did not use services was minimal (Saksena et al. 2006). Our analysis has shown that around $26.0 \%$ and $11.9 \%$ of the population were sick with chronic and acute conditions, respectively. The consequence of chronic diseases besides the implied increase in catastrophic health expenditure reduces the labour force and hence the income of the households. Therefore, the measure of the catastrophic health spending presented in this article may also underestimate the real prevalence among the population and most importantly among the poor. However, these findings deserve cautious interpretation, because several factors could affect such behaviour. One of them is the perception of seriousness of the chronic illness and the special nature of some chronic diseases such as HIV and/or AIDS. In addition, people with chronic diseases may choose self- or traditional treatment as the cost of consulting a traditional healer is usually lower than visiting a doctor, especially for the poor and those who mostly reside in rural areas. Our results show that there is an improvement in adult's health status in 2012 compared with 2008 data, which can be attributed to the concerted government efforts in reducing health inequalities. Besides the introduction of Social Health Insurance (SHI) which will stand to substantially expand insurance coverage and therefore perhaps is likely to play a more important role in improving access to health care and protect households from the impoverishing effects of catastrophic health expenditure.

\section{Conclusion}

Our results show that health insurance coverage protects against catastrophic expenditures, which contributes to the well-being of households. In addition, the OOP health expenditure is broadly regressive. However, the problem is that medical insurance is only granted to those who can afford to pay directly or through their employers. In contrast, the majority of the poorest in rural areas work in the informal sector or in traditional work, which does not provide 
medical cover. However, consulting with traditional healers may alleviate the impact of facing catastrophic health expenditures and their costs are far less than that of a medical doctor. In contrast, the main factors that lead to exposure of catastrophic expenditures are the poorest households, spending money on hospitalisation and spending money on medical supplies. Thus, reducing the prevalence of catastrophic health expenditure as a policy objective of the government can be achieved by focusing on increased financial protection offered to the poor and expanding governmentfinanced benefits for the poor and chronically diseased by including and expanding hospitalisation coverage and adding medical supplies benefits.

\section{Acknowledgements Competing interests}

The authors declare that they have no financial or personal relationships which may have inappropriately influenced them in writing this article.

\section{Authors' contributions}

All authors equally contributed to the research and writing of this article.

\section{References}

Berki, S., 1986, 'A look at catastrophic medical expenses and the poor', Health Affairs 5(4), 138-145. https://doi.org/10.1377/hlthaff.5.4.138
Botha, C. \& Michael, H., 2008, Financing South Africa's national health system through national health insurance: Possibilities and challenges, HRSC press.

Nyonator F. \& Kutzin, J., 1999, 'Health for some? The effects of user fees in the Volta Region of Ghana', Health Policy and Planning 14(4), 329-341.

Pandayachee, V., 2006, The development decade? Economic and social change in South Africa 1994-2004, HRSC press, pp. 334-338.

Saksena P., Xu, K. \& Carrin, G., 2006, The impact of universal insurance program on catastrophic health expenditure: Simulation analysis for Kenya, Discussion Paper no. 8, World Health Organization, Geneva.

Sen, A., 2002, 'Health perception versus observation', British Medical Journal 324(7342), 860-861. https://doi.org/10.1136/bmj.324.7342.860

Southern Africa Labour and Development Research Unit. National Income Dynamics Study, Research Unit [producer], 2013, Cape Town: Data First [distributor], 2013, 2012, Wave 3 [dataset], Version 1, Southern Africa Labour and Development, Cape Town.

Su, T.T., Kouyaté, B. \& Flessa, S., 2006, 'Catastrophic household expenditure for health care in a low-income society: A study from Nouna District, Burkina Faso', Bulletin of World Health Organization 84(1), 21-27. https://doi.org/10.2471/BLT.05. 023739

Wagstaff, A. \& van Doorslaer, E., 2003, 'Catastrophe and impoverishment in paying for health care: With applications to Vietnam 1993-1998', Health Economic 12(11), 921-934. https://doi.org/10.1002/hec.776

Wagstaff, A., 2006, 'The economic consequences of health shocks: Evidence from Vietnam', Journal of Health Economics 26: 82-100. https://doi.org/10.1016/j. jhealeco.2006.07.001

Wter, H.R., Anderson, G.F. \& Mays, J., 2004, 'Measuring financial protection in health in the United States', Health Policy 69, 339-349. https://doi.org/10.1016/j. healthpol.2004.01.003

Wyszewianski, L., 1986, 'Financially catastrophic and high-cost cases: Definitions, distinctions, and their implications for policy formulation', Inquiry 23(4), 382-394.

Xu, K., Evans, D.B., Carrin, G., Aguilar-Rivera, A.M., Musgrove, P. \& Evans, T., 2007, 'Protecting household from catastrophic health spending', Health Affair 26(4), 972-983. https://doi.org/10.1377/hlthaff.26.4.972

Xu, K., Klavus, J., Aguilar-Rivera, A.M., Carrin, G., Zeramdini, R. \& Murray, C.J.L., 2003a, 'Summary measures of the distribution of household financial contributions to health', in C.J.L. Murray \& D.B. Evans (eds.), Health systems performance assessment: Debates, methods and empiricism, Volume Chapter 40, World Health assessment: Debates,

Xu, K., Evans, D.B., Kawabata, K., Zeramdini, R., Klavus, J. \& Murray, C.J.L., 2003b, 'Household catastrophic health expenditure: A multi-country analysis', Lancet 362, 111-117. https://doi.org/10.1016/S0140-6736(03)13861-5 